\title{
Serum monoclonal immunoglobulins in childhood
}

\author{
FRANÇOISE DANON and MAXIME SELIGMANN \\ From the Department of Immunochemistry, Research Institute on Blood Diseases, Hôpital Saint-Louis, Paris, France
}

\begin{abstract}
Danon, F., and Seligmann, M. (1973). Archives of Disease in Childhood, 48, 207. Serum monoclonal immunoglobulins in childhood. Of 18 children with monoclonal immunoglobulins in their sera, 13 had a primary or secondary immunodeficiency. The monoclonal immunoglobulin belonged to each of the three main Ig classes, and in 3 children multiple monoclonal components were detected. The level of the monoclonal component exceeded $0.5 \mathrm{~g} / 100 \mathrm{ml}$ in 7 cases. The monoclonal immunoglobulin disappeared spontaneously in 9 children. The significance of this homogeneous component and the importance of the underlying immunodeficiency are outlined.
\end{abstract}

Monoclonal immunoglobulins (Ig) are mainly associated with multiple myeloma and Waldenström's macroglobulinaemia. However, during recent years several reports have been published concerning monoclonal Ig without evidence of such haematological diseases (Osserman and Takatsuki, 1965; Hallen, 1967; Hobbs, 1967; Danon, Clauvel, and Seligmann, 1967; Michaux and Heremans, 1969). These Ig abnormalities, with or without clinical manifestations, have usually been detected in adults and elderly people, but monoclonal Ig have occasionally been reported in childhood. The present report concerns 18 children; we show that in childhood monoclonal Ig is most often associated with primary or secondary immunodeficiency and that it may disappear spontaneously.

\section{Material and methods}

Seventy-three serum samples from 18 children were studied by electrophoresis and immunoelectrophoresis. Most of the children were being followed in our clinic on account of haematological or immunological diseases, and were submitted to a systematic Ig survey. In a few a sudden increase in the erythrocytic sedimentation rate sometimes provided stimulus to perform immunoelectrophoretic analysis.

Electrophoresis was performed in $1 \%$ agar gel, the proteins being stained with amidoblack, and in cellulose acetate, the level of the homogeneous components being estimated as a percentage of the total uptake of ponceau red. Immunoelectrophoretic analysis was carried out in barbitone buffer $p \mathrm{H} 8 \cdot 2$, ionic strength 0.05 , with a variety of rabbit antisera prepared in our laboratory and conveniently absorbed, including antisera specific for $\gamma, \mu, \alpha, \delta, \kappa$, and $\lambda$ chains.

Quantitation of the immunoglobulin classes not

Received 30 June 1972 including the monoclonal components was performed by radial diffusion in agar with specific antisera incorporated into the gel (Mancini, Carbonara, and Heremans, 1965). Antinuclear antibodies were sought by the indirect immunofluorescence technique on liver sections. Antibodies to human and rabbit $\gamma$-globulin were detected by the latex F II and Waaler Rose reactions.

Our criteria for defining a population of Ig molecules as 'monoclonal' were (1) an abnormal bow reacting with antisera corresponding to only one type of heavy and light chain on immunoelectrophoresis; (2) a discrete homogeneous peak with sharp borders migrating by electrophoresis in the same region as the immunoelectrophoretic bow. Both criteria were fulfilled in 14 of 18 cases. In the other cases, the monoclonal $\mathrm{Ig}$ level was not sufficient to induce a sharp peak but the light chain typing, either by immunoelectrophoresis of the whole serum or after sucrose density gradient ultracentrifugation for IgM components confirmed its antigenic homogeneity.

We have excluded from this study two kinds of abnormalities. Firstly, we do not report here the cases with a monoclonal protein characteristic of the $\alpha$-chain disease (Seligmann et al., 1968) which occurs in young adults and children (Seligmann, Mihaesco, and Frangione, 1971). Secondly, we do not consider as monoclonal the IgG showing only a restricted cathodal electrophoretic mobility, which are often encountered in the sera of young children (Golebiowska and Rowe, 1967). In our own experience these IgG molecules with restricted electrophoretic heterogeneity always shared both $\kappa^{-}$and $\lambda$-chains and could not therefore be considered as antigenically homogeneous.

The criterion for the disappearance of the monoclonal Ig was the failure to detect on subsequent sera homogeneous protein previously detectable by electrophoresis and/or immunoelectrophoresis (Danon and Seligmann, 1972). 


\begin{tabular}{|c|c|c|c|c|c|c|}
\hline \multirow{2}{*}{ Case No. } & \multirow{2}{*}{ Diagnosis } & \multirow{2}{*}{$\begin{array}{l}\text { Immuno- } \\
\text { suppressive } \\
\text { therapy` }\end{array}$} & \multirow{2}{*}{ Age } & \multicolumn{3}{|c|}{ Monoclonal Ig type $(\mathrm{g} / 100 \mathrm{ml})$} \\
\hline & & & & & $<0.5$ & $>0.5$ 蛋 1 \\
\hline
\end{tabular}

^Before discovery of monoclonal Ig; †Interval between finding of monoclonal Ig and first electrophoresis or immunoelectrophoresis showk no

\section{Results}

The most important results are summarized in the Table.

Immunoglobulin findings. The monoclonal Ig belonged to any one of the three main Ig classes, while in 3 patients multiple monoclonal Ig were detected.

The level of the monoclonal Ig was over 0.5 $\mathrm{g} / 100 \mathrm{ml}$ in 7 cases and as high as $1 \mathrm{~g} / 100 \mathrm{ml}$ in 3 cases (Cases 5, 7, and 13 of the Table). The level of serum polyclonal Ig belonging to classes other than that of the monoclonal components was normal in 9 , increased in 7 , and decreased only in 2 cases. This finding was remarkable in several patients with immunodeficiency diseases.

Antinuclear factors were found in 5 of 16 cases with titres as high as $1 / 100$ in 2 cases. No DNA antibodies were detected by complement fixation or precipitin tests. Rheumatoid factor was found in 3 sera. Two of these had both antinuclear and anti- $\gamma$-globulin antibodies.

The proteinuria was investigated in 6 patients. Two of them showed excretion of a very small amount of Bence-Jones protein, detectable only after urine concentration (Cases 5 and 10). The CSF was investigated in 2 patients (Cases 5 and 13), monoclonal IgG being found in both.

Clinical findings. The clinical diagnoses are summarized in the Table. It is noteworthy that at least 5 children suffered from a primary immuno- deficiency. At the time of examination they had never received $\gamma$-globulin injections (nor thymus or marrow grafts). 6 children had leukaemia or lymphosarcoma, all receiving chemotherapy, and 4 being in complete remission. In 5 cases the monoclonal Ig was known not to be present at the time of diagnosis and appeared at a later stage, as shown by successive electrophoretic patterns. As a rule, these serial studies were performed at intervals of several weeks or months so that the precise time of monoclonal Ig appearance could not be ascertained except in the following case.

Case 7. This child was first seen in 1967 for an acute lymphoblastic leukaemia. A complete remission was induced. During the following three years he was under maintenance therapy with mercaptopurine and amethopterine, with reinductions at regular intervals with prednisone, vincristine, and rubidomycin. He was admitted to hospital in October 1970 for an unexplained fever (relapse of the leukaemia was excluded). The sedimentation rate was $25 \mathrm{~mm}$ in the first hour and the serum electrophoresis pattern was normal (Fig. (1)). 12 days later the sedimentation rate had risen to 160 $\mathrm{mm}$ and the serum protein electrophoresis revealed a discrete $\gamma$-peak (Fig. (2)). Immunoelectrophoresis showed a diffuse increase of $\operatorname{IgM}$ and $\operatorname{IgG}$ with a monoclonal $\mathrm{K}$ IgG. Virological and serological investigations led to the diagnosis of cytomegalovirus infection. Cytomegalovirus antibodies reached a titre of $1 / 1600$ and decreased thereafter. 


\begin{tabular}{|c|c|c|c|c|}
\hline Other Ig classes & Antinuclear factor & Rheumatoid factor & Additional features & $\begin{array}{c}\text { Disappearance } \\
\text { of } \\
\text { monoclonal Ig† }\end{array}$ \\
\hline 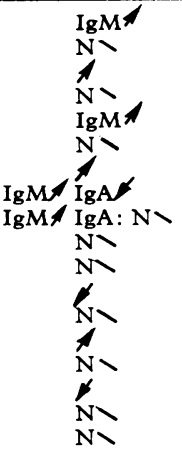 & $\begin{array}{l}- \\
\text { ND } \\
- \\
+ \\
- \\
+ \\
+ \\
+ \\
+ \\
- \\
\text { ND } \\
- \\
-\end{array}$ & $\begin{array}{l}- \\
\text { ND } \\
+ \\
- \\
- \\
- \\
+ \\
\frac{+}{N D} \\
- \\
-\end{array}$ & $\begin{array}{l}\text { Cytomegalovirus infection } \\
\text { Cytomegalovirus infection } \\
\text { Cytomegalovirus infection } \\
\text { Cytomegalovirus infection }\end{array}$ & $\begin{array}{l}2 \mathrm{mth} \\
1 \mathrm{yr} \\
1 \mathrm{yr} \\
2 \mathrm{mth} \\
15 \mathrm{dy} \\
4 \mathrm{dy} \\
8 \mathrm{mth}\end{array}$ \\
\hline
\end{tabular}

more such component; ¥Dalloz et al. (i965); \$Loirat, Danon, and Broyer (1971). ND, not done; N, normal.

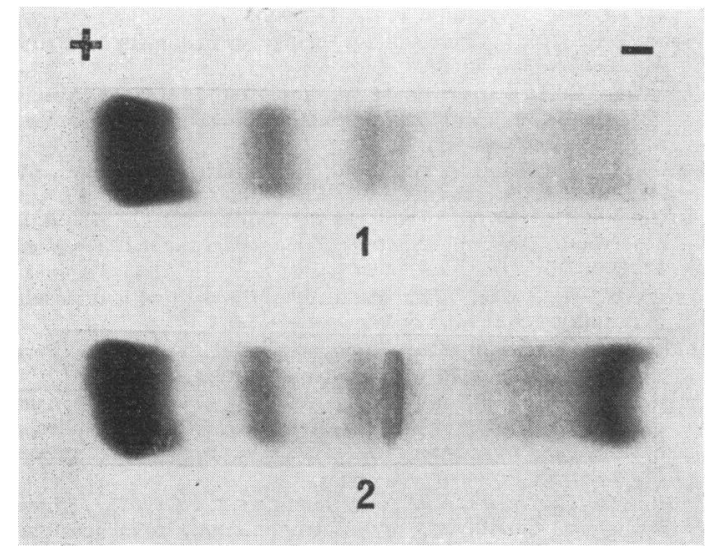

FIG.-Successive agar gel electrophoresis of the sera of Case 7 (lymphoblastic leukaemia): (1) 29 October 1970, (2) 11 November 1970.

The child recovered. The level of the monoclonal Ig slowly decreased and finally disappeared after 6 months.

Follow-up studies. We have never observed any increase in the level of the monoclonal Ig after initial detection, though many of the children could be followed for only a limited period, since 10 of them died from the underlying disease.

The main finding during the follow-up studies was the transience of the monoclonal Ig in 9 cases. In 7 of these children, its disappearance occurred spontaneously (reported in detail elsewhere by Danon and Seligmann, 1972). As shown in the Table, the interval between its detection and disappearance varied between 4 days and 1 year.

\section{Discussion}

This report clearly shows that the occurrence of serum monoclonal $\mathrm{Ig}$ is not a very exceptional event during childhood and that such immunoglobulin abnormalities may be detected in very young infants as well as in older children. None of the 18 children reported in the present study was affected with myeloma or Waldenström's macroglobulinaemia, emphasizing that it is probably only $\alpha$-chain disease which in childhood leads to a presumably malignant plasmacytic proliferation characterized by a monoclonal Ig (Irunberry et al., 1970; Stoop et al., 1971; Seligmann et al., 1971).

As far as the associated diseases are concerned, the striking finding in the present study is that 13 of the 18 children were affected with primary or secondary immunodeficiency. The common diagnosis in the primary immunodeficiency group was either severe combined immunodeficiency or the Wiskott-Aldrich syndrome. Among the other patients, 7 were under immunosuppressive therapy when the monoclonal Ig was detected, most suffering from a malignant haematological disease.

Our findings may be partly related to the fact that our department is mainly devoted to haematology and immunology. However, most of the case reports documenting monoclonal Ig in childhood also 
concern patients with immunodeficiency diseases: Wiskott-Aldrich syndrome (Radl et al., 1967; Blaese et al., 1971), ataxia telangiectasia (Cawley and Schenken, 1970), and severe combined immunodeficiency (Stoop, Ballieux, and Weyers, 1962; Schaller et al., 1966; Becroft and Douglas, 1968). In these cases and in those reported here, the patients had received neither $\gamma$-globulin nor thymus or bone marrow grafts. In contrast, Harboe et al. (1966) and Radl et al. (1972) have also documented the appearance of monoclonal Ig after the grafting of lymphoid cells into infants affected with severe combined immunodeficiency.

The occurrence of monoclonal Ig associated with acute leukaemia has been reported by Stoop et al. (1968), Lindqvist, Ragab, and Osterland (1970) and Hitzig and Jako (1971). These 3 children, as well as our 5 were all treated by immunosuppressive therapy. One of our children (Case 12) was not affected with a malignant haematological disease but had been treated for 2 years by immunopressive therapy for a nephrotic syndrome: 3 months after withdrawal of treatment, a subacute sclerosing panencephalitis appeared and led to death 6 months later (Loirat et al., 1971).

These data strongly suggest that the appearance of monoclonal $\mathrm{Ig}$ is favoured by an underlying immunodeficiency whether primary or secondary. Though a precise antibody activity of the homogeneous component has not been proven, it seems probable that monoclonal $\mathrm{Ig}$ in childhood often represents homogeneous antibodies similar to the antibodies of restricted heterogeneity elicited in man and rabbits by immunization with carbohydrate antigens (Krause, 1970). In several cases the appearance and detection of the monoclonal Ig coincided with a viral infection. Monoclonal Ig has recently been found in several newborns affected with congenital toxoplasmosis (C. Griscelli, G. Desmont, and D. Frommel, personal communication, 1972). It is of great interest that in half of our cases the monoclonal components were transient. This transient character is similar to the findings in rabbit immunized with streptococcal carbohydrates (Osterland et al., 1966). Immunodeficiency could well be a predisposing factor for some antigenic stimuli to induce formation of uniform antibodies. This hypothesis is in accordance with previous findings in animals in which the immunological defects were induced experimentally (Humphrey, Parrot, and East, 1964; Pierce, Chubb, and Long, 1966).

REFERENCES

Becroft, D. M. O., and Douglas, R. (1968). Thymic alymphoplasia monoclonal gammopathy, and Pneumocystis Carinii pneumonia in an infant. Archives of Disease in Childhood, 43, 444.
Blaese, R. M., Strober, W., Levy, A. L., and Waldmann, T. A. (1971). Hypercatabolism of IgG, IgA, IgM and albumin in the WiskottAldrich syndrome. A unique disorder of serum protein metabolism. Fournal of Clinical Investigation, 50, 2331.

Cawley, L. P., and Schenken, J. R. (1970)). Monoclonal hypergammaglobulinemia of the $\gamma M$ type in a nine-year-old girl with ataxia-telangiectasia. American fournal of Clinical Pathology, 54, 790.

Dalloz, J. C., Castaing, N., Nezelof, C., and Seligmann, M. (1965). Paraprotéinémie transitoire de type $\gamma$. Observation chez un nourrisson atteint du syndrome d'Aldrich. Presse Médicale, 73, 1541 .

Danon, F., Clauvel, J. P., and Seligmann, M. (1967). Les 'paraprotéines' de type IgG et IgA en dehors de la maladie de Kahler. Revue Française d'Etudes Cliniques et Biologiques, 12, 681.

Danon, F., and Seligmann, M. (1972). Transient human monoclonal immunoglobulins. Scandinavian fournal of Immunology, $1,323$.

Golebiowska, H., and Rowe, D. S. (1967). Immunoglobulin G of restricted electrophoretic mobility in certain human sera. Clinical and Experimental Immunology, 2, 275.

Hallen, J. (1967). Discrete gammaglobulin (M) components in serum. Acta Medica Scandinavica, Suppl., 462, 127.

Harboe, M., Pande, H., Brandtzaeg, P., Tveter, K. J., and Hjort, P. F. (1966). Synthesis of donor type $\gamma$ G-globulin following thymus transplantation in hypo- $\gamma$-globulinaemia with severe lymphocytopenia. Scandinavian fournal of Haematology, 3, 351.

Hitzig, W. H., and Jako, J. (1971). Monoclonal immunoglobulins in children. In Protides of the Biological Fluids, Proceedings of the 18th Colloquium. Bruges, 1970, p. 139. Ed. by H. Peeters. Pergamon Press, London.

Hobbs, J. R. (1967). Paraproteins, benign or malignant ? British Medical fournal, 3, 699.

Humphrey, J. H., Parrot, D. M. V., and East, J. (1964). Studies on globulin and antibody production in mice thymectomized at birth. Immunology, 7, 419.

Irunberry, J., Benallegue, A., Illoul, G., Timsit, G., Abbadi, M., Benabdallah, S., Boulekkine, T., Ould-Aoudia, J. P., and Colonna, P. (1970). Trois cas de maladie des chaines alpha observés en Algérie. Nouvelle Revue Française d'Hématologie, $10,609$.

Krause, R. M. (1970). The search of antibodies with molecular uniformity. Advances in Immunology, 12, 1.

Lindqvist, K. J., Ragab, A. H., and Osterland, C. K. (1970). Paraproteinemia in a child with leukemia. Blood, 35, 213

Loirat, C., Danon, F., and Broyer, M. (1971). Panencéphalite subaigue sclérosante survenant au cours d'un syndrome néphrotique traité par les immunosuppresseurs. Archives Franfaises de Pédiatrie, 28, 1083.

Mancini, G., Carbonara, A. O., and Heremans, J. F. (1965). Immunochemical quantitation of antigens by single radial immunodiffusion. Immunochemistry, 2, 235.

Michaux, J. L., and Heremans, J. F. (1969). Thirty cases of monoclonal immunoglobulin disorders other than myeloma or macroglobulinemia. American fournal of Medicine, 46, 562.

Osserman, E. F., and Takatsuki, K. (1965). Considerations regarding the pathogenesis of the plasmacytic dyscrasias. In Gamma Globulins. Ed. by S. E. Bjorkman. Series Haematologica, 4, 28. Munksgaard, Copenhagen.

Osterland, C. K., Miller, E., Karakawa, W. W., and Krause, R. M. (1966). Characteristics of streptococcal group-specific antibody isolated from hyperimmune rabbits. Fournal of Experimental Medicine, 123, 599.

Pierce, A. E., Chubb, R. C., and Long, P. L. (1966). The significance of the Bursa of Fabricius in relation to the synthesis of $7 S$ and 19S immune globulins and specific antibody activity in the fowl. Immunology, 10, 321.

Radl, J., Dooren, L. J., Eijsvoogel, V. P., Vanwent, J. J., and Hijmans, W. (1972). An immunological study during posttransplantation follow-up of a case of severe combined immuno deficiency. Clinical and Experimental Immunology, 10, 367.

Radl, J., Masopust, J., Houstek, J., and Hrodek, O. (1967). Paraproteinemia and unusual dysgammaglobulinaemia in a case of Wiskott-Aldrich syndrome: an immunochemical study. Archives of Disease in Childhood, 42, 608. 
Schaller, J., Davis, S. D., Ching, Y. C., Lagunoff, D., Williams, C. P. S., and Wedgwood, R. J. (1966). Hypergammaglobulinaemia, antibody deficiency, autoimmune haemolytic anaemia, and nephritis in an infant with a familial lymphopenic immune defect. Lancet, 2, 825.

Seligmann, M., Danon, F., Hurez, D., Mihaesco, E., and Preud 'Homme, J. L. (1968). Alpha-chain disease: a new immunoglobulin abnormality. Science, 162, 1396.

Seligmann, M., Mihaesco, E., and Frangione, B. (1971). Studies on alpha-chain disease. Annals of the New York Academy of Sciences, 190, 487.

Stoop, J. W., Ballieux, R. E., Hijmans, W., and Zegers, B. J. M (1971). Alpha-chain disease with involvement of the respira- tory tract of a Dutch child. Clinical and Experimental Immuno$\log y, 9,625$.

Stoop, J. W., Ballieux, R. E., and Weyers, H. A. (1962). Paraproteinaemia with secondary immune globulin deficiency in an infant. Pediatrics, 29, 97.

Stoop, J. W., Zegers, B. J. M., Van Der Heiden, C., and Ballieux, R. E. (1968). Monoclonal gammopathy in a child with leukemia. Blood, 32, 774.

Correspondence to Dr. M. Seligmann, Departmert of Immunochemistry, Research Institute on Blood Diseases, Hôpital Saint-Louis, Paris 10e, France. 